\title{
PROCESSING AND CHARACTERIZATION OF ALUMINUM METAL MATRIX COMPOSITES: AN OVERVIEW
}

\author{
Mudasar Pasha B.A. ${ }^{1}$ and Mohammed Kaleemulla ${ }^{2}$ \\ ${ }^{1}$ Department of Mechanical Engineering GMIT Davanagere, Karnataka, India \\ ${ }^{2}$ Department of Mechanical Engineering UBDTCE Davanagere, Karnataka, India
}

Received: January 12, 2018

\begin{abstract}
An increased interest is observed in recent years in the processing of aluminum metal matrix composites (AMMCs) due to their remarkable properties such as light in weight, very high strength, environmental resistance, corrosion resistance, and low thermal coefficient of expansion compared to conventional metal and alloys. This leads to superior compressive strength, for fuel cell applications, low density and low cost for automotive and small engine applications. Homogeneous distribution of the reinforcement phase in turns improves hardness and ultimate tensile strength for lightweight applications, especially aeronautical and high-speed train industries. Uniform distribution of reinforcement directly influences properties and quality of the composite material. And develop a conventional low-cost method of producing metal matrix composites to obtain a homogenous dispersion of reinforcing materials. In this review article, processing and characterization of aluminum metal matrix composites have been reviewed. The Point of convergence is given to the new fabrication techniques, their physical and mechanical characterization. Substantially this review article censoriously reviews the present and past state of understanding of the processing of aluminum metal matrix composites with different reinforcement. The resulting failure mechanisms are discussed. Instructions are given to clarify open questions related to the fabrications of aluminum metal matrix composites.
\end{abstract}

\section{INTRODUCTION}

A significant increase in the development of light metal matrix composites has been achieved in recent years, so that they could be introduced into the most important applications. AMMCs are attractive in various applications because of their improved physical and mechanical properties. Generally, physical and mechanical properties are more often determined by the fabrication technique. Types of the fabrication process and particle size are the effective factors influencing the physical and mechanical properties of the composites [1]. Continuous fiber reinforced MMCs are expensive and their applications are therefore limited to some extent. But discontinuously reinforced MMCs results in improved properties such as both mechanical and physical that cannot be achieved using conventional engineering alloys [2]. These enhanced material properties are because of the interaction between the metallic matrix and the reinforcement. Less interfacial attraction between the matrix and reinforcement causes the damage to the matrix material. Improved processing and coating techniques can be used to control destructive matrices and the reinforcement interactions. The application of pressure can be used to impel close contact between fiber and matrix and thus promote wetting; squeeze casting is one such example for this. Commonly used processing methods for the processing of AMMC are, Solid-state processes, In situ processes, and Spray-forming of particulate AMMCs, etc. A wide variety of metal matrices and control of fiber orientation and volume

Corresponding author: M. Pasha B.A., e-mail: mudasarpasha@gmail.com 
fraction can be very easily achieved using solid state technique. But the process is expensive because of long time, high processing temperatures and pressures, and a limitation on the complexity of shapes that can be produced. Hülya Kaftelen et al. [3] studied the structure properties of reinforced composites. And they found no evidence of any interfacial reaction products between $\mathrm{Al}$ and TiC reinforcements. Peng et al. [4] claim that modified squeeze casting, provides an uniform distribution of reinforcement, and high elastic modulus compare to conventional method of composites. Tong et al. [5] found that spray-forming of particulate AMMCs is generally automated and quite the fastest method of producing composite materials. And they suggested that, properties of the composite depend on the interface region, as the interface discontinuity is due to one or more material parameters. The disadvantage of this process is quite expensive. The liquid metallurgy technique is the most significant and economical of all the available techniques in production of AMMCs [6]. The processing of materials in liquid form is commonly known as casting. The conventional method of casting MMCs experiences various problems like mixing of reinforcement, porosity, voids which may leads to decrease in strength and hardness of the composites. Recent developments in the fabrication of AMMCs like stir casting, Squeeze casting, Spray deposition; ultrasonic assisted castings, and reactive are the various liquid state processing methods. Stir casting is the most significant and fastest method for the production of Aluminum matrix composites to fulfill the need of material requirements in various fields of applications [7]. The aim of this report is to critically review the different processing techniques used to obtain aluminium metal matrix composites.

\section{PROCESSING OF ALUMINUM METAL MATRIX COMPOSITES WITH DIFFERENT REINFORCEMENT: RESEARCH HISTORY}

Processing of aluminium metal matrix can be classified as solid state and liquid state. Processing of AMMCs by Melting metallurgical processes such as the compo-casting or melt stirring, gas pressure infiltration, and squeeze casting or pressure casting being of greater importance than any other processes [8]. Mitsuaki Matsumuro and Tadashi Kitsudo $[9,10]$ found that hydrogen degassing helped to produce good distribution of $\mathrm{SiCp}$ within the aluminum matrix and decrease porosity. They also claim that, casting temperature at $953.15 \mathrm{~K}\left(680^{\circ} \mathrm{C}\right)$ in the liquid state plays a key role in improving density and hardness properties. Redstern and Hamouda [11,12] found that the size of the $\mathrm{Al}_{3} \mathrm{Ni}$ decreased with the decreasing processing temperature and stirring time, stirring speed and stirring time, low pressure and temperature, grain size, and weight percentages of reinforcement, fabrication methods, exert significant effect on the mechanical properties of composite material thereby influencing the micro structural evolution of material. In this section, a few major factors affecting the fabrication process of aluminium metal matrix composites, fabrication methods, grain size and weight percentage of reinforcement, stirring speed and stirring time, low pressure and temperature are discussed.

\subsection{Fabrication methods}

The processing technique is one of the most important key parameter in the development of AMMCs. An improved property of the composite and its cost is determined by the suitable fabrication method. The focus on the selection of the suitable fabrication method is the desired type, composition and weight percentage distribution of the reinforcement components, and the matrix alloy and the application. The major drawback of conventional method of fabrication of AMMC are lesser wettability of reinforcement particle with the matrix material, increase in the level of micro porosity, non uniform distribution of fine particles and processing cost, etc. Table 1 presents an overview of published work dealing with different manufacturing methods, their characteristic features, and drawback of the manufacturing methods. At the end of this section, discussion and suggest the most significant and economical method of manufacturing process. AMMCs can be fabricated from different methods as shown in Table 1. Compocasting is one of the liquid state processes, in which the reinforcement particles are added to a solidifying melt within its liquid-solid zone while being vigorously agitated. This will minimizes the segregation and almost uniform distribution of reinforcement particles. Accordingly, to fabricate high quality particulate reinforced $A M M C s$ with desirable mechanical properties through compo-casting technique, Amirkhanlou and Niroumand [13] found an increase in mechanical strength, and wear resistance of the composites than stir casting method. Karantzalis et al. [14] reported that, the significant strengthening of the composite using flux casting technique is, due to strong interfacial bonding by 
Table 1. Overview of previous research work of processing of AMMC using different techniques and their characteristics.

\begin{tabular}{|c|c|c|c|}
\hline $\begin{array}{l}\text { Matrix material + } \\
\text { reinforcement }\end{array}$ & $\begin{array}{l}\text { Fabrication } \\
\text { methods }\end{array}$ & Characteristic & $\begin{array}{l}\text { Drawback(Achieving uni- } \\
\text { form distribution of rein- } \\
\text { forcement) }\end{array}$ \\
\hline
\end{tabular}

\begin{tabular}{ll}
\hline $99.7 \% \mathrm{Al}+10$ & $\begin{array}{l}\text { Flux-casting } \\
\text { Technique }\end{array}$ \\
$\mu \mathrm{mTiC}$ &
\end{tabular}

Appreciable strength between matrix and reinforcement, higher modulus and lower ductility

$7075 \mathrm{Al}+\mathrm{A} 348+$ Powder metallur-

$\mathrm{Sic}+$ Alpha $\mathrm{Al}_{2} \mathrm{O}_{3}, \quad$ gy \& liquid cast $\mathrm{SiCp}$

$6061 \mathrm{Al}+\operatorname{Sic} 60-90$

$\mu \mathrm{m}, \mathrm{Al}_{2} \mathrm{O}_{3} 30-50$

$\mu \mathrm{m}$, red mud 103$150 \mu \mathrm{m}$

$A 384 A+\operatorname{Sic} 60 \mu \mathrm{m}$

$7005 \mathrm{Al}+\mathrm{Al}_{2} \mathrm{O}_{3} 10-$ $21 \mu \mathrm{m}$

Molten commercial

- purity Aluminum (cp-Al) and $7075 \mathrm{Al}$ alloy + Crystalline Mullite $\left(3 \mathrm{Al}_{2} \mathrm{O}_{3}\right.$ $2 \mathrm{SiO}_{2}$ ) and 55 vol. \% Amorphous Silica $\left(\mathrm{SiO}_{2}\right), 15-75 \mu \mathrm{m}$ A356 +Alumina Powder with size of $50 \mu \mathrm{mand} 20 \mu \mathrm{m}$ metal technology

Improved strength and ductility up to $10 \%$ increase in $\mathrm{Al}_{2} \mathrm{O}_{3}$

Improve micro hardness and wear resistant

Better Hardness of the composites

Ingot Metallurgy Increased Elastic Moduli Process

Liquid metal infiltration

Improved maximum strength
Not up to the mark: Because of conventional method, Gravity isolation of dispersed phase.

Not up to the mark: Because of conventional method, Gravity isolation of dispersed phase.

Fairly uniform distribution of reinforcement

Maximum stirring speed and time responsible for fairly uniform distribution of reinforcement

Fairly uniform distribution of Reinforcement

Fairly uniform distribution of

14
Improvement inyield strength, ultimate tensile strength,compression
ReinforcementNearly uniform distributiondue to nano size reinforcement by compo - casting than stir casting nucleation of solid Al on the TiC particle surface. They also reported that, little effect on the modulus of composites. This is in agreement with Redstern et al. [11] worked out on powder metallurgy technique, they found that improvement in mechanical properties of oxide-dispersion-strengthened aluminum composites, and obtained as predicted young's modulus. Yuyong Chem and Lchung [15] reported, that better thermal expansion coefficient, compressive strength, tensile strength and hardness of the composites by Liquid metal infiltration method. Dobrzañski et al. [16] proved that developed technology ensures expected structure and can be used in practice. In continuation to the previous work, Dobrzañski et al. [17] proved that developed technology of manufacturing of composite materials based on the porous ceramic $\mathrm{Al}_{2} \mathrm{O}_{3}$ preforms infiltrated by liquid aluminium alloy, ensures expected structure and twice the increase in strength, which can be used in practice. Muratogl et al. [18] concluded that, it is possible to obtain new composite material with the required structure for automotive applications using pressure infiltration method. This is in agreement with WodarczykFligier et al. [19] they concluded that, it is possible to manufacture composite materials with good sur- 
face quality, but it is more energy consuming than powder metallurgy and this is the main restriction of its application. A more recent work by Dobrzañski et al. [20] show that, the new composite materials obtained by the method of porous sintered framework pressure infiltration with desired microstructure and properties, being a cheaper alternative for ceramic fibers. A similar result has been reported by Chawla et al. [21] but the microstructure of the composites revealed that alignment and interparticle bond strength was not as high as that observed for the extruded composite. Anodizing and accumulative roll bonding processes by Roohollah Jamaati and Mohammad Reza Toroghinejad [22] claim that, uniform distribution of reinforcement, pores free, and higher tensile strength compared to the base material. This shows a good sign of advancement in the field of AMMCs. Magneto chemistry reaction Zhao Yu-Tao et al. [23] pointed out that, the interfaces between the in situ particles and the aluminum matrix are net and no interfacial outgrowth is observed, due to the strong vibration induced by the applied magnetic field in the aluminum melt. Advanced Shear Technology Barekar et al. [24] with the aim to fabricate aluminium metal matrix composites has also been investigated. However, research in these areas will not be reviewed here; this work focuses on the use of stir casting method of the fabrication of AMMCs. In the above discussion part, various researchers worked out on various fabrication techniques, they found excellent improved properties of the composites, but at higher cost and complexity of the process. Compared with other techniques described above conventional method has several advantages such as simplicity, low cost of processing, manufacturing of intricate components, and near-net shape components. The degree of being easily fabricated AMMCs by stir casting method with various grain size reinforcement is summarized in Table 1. Muhammad hayat jokhio et al. [25] synthesized aluminium 7000 series composites by the addition of mainly $\mathrm{Al}_{2} \mathrm{O}_{3}$ found the good responses to the strength and ductility up to $10 \%$ $\mathrm{Al}_{2} \mathrm{O}_{3}$ particles. In situ process produces composite material in one step, thus avoiding the difficulties inherent in combining the separate components as doing in a typical composite processing. The relative size and distribution of the reinforcement phase can be controlled by simply controlling the solidification rate. But the solidification rate is limited to some extent to the need to maintain a stable growth front which requires a high temperature gradient [26]. Different methods have been used, although stir casting is preferred due to environmen- tal and cost effective method. Table 1 reveals that, fabrication of AMMC by stir casting technique is the most suitable method for nearly uniform distribution of reinforcement and having good characteristic features compared to other fabrication methods. It is more economical and has the advantage of being able to use well proven casting process of the production of AMMCs. With increasing experience and some improvement in understanding processing parameters the development of new technologies has evolved significantly [28]. The authors found that by a novel method of reinforcement, TiB whisker acquire a branched shape structure which could strongly link the adjacent $\mathrm{Ti}-6 \mathrm{Al}-4 \mathrm{~V}$ particles, which in turn increases the tensile strength compared to unreinforced Ti-6Al-4V alloy. Chen GuoQin et al. [29] worked on size (micron) and shape (angular and spherical) of reinforcement particles, using squeeze casting technique. They reported that, subjecting to thermal cooling cycle treatment of thermal expansion behaviour of particulate reinforced aluminium metal matrix composites, composites are free of porosity and uniform distribution of particles can be achieved. Complex features have been added to alter the flow of molten metal, mixing and reduce processing time. Chi-Hoon Jeon et al. [30] pointed out that reinforcements are successfully mixed into the aluminum matrix by friction stir processing. If maximum stirring speed and time is maintained properly, it is suggested that the most significant method of manufacturing process is stir casting process. Authors $[31,32]$ reported that equal channel angular pressing is a relatively new technology in material fabrication which produces near net shape preforms. Presented herein are the preliminary results of the stir casting process which is a cost effective method compare to other methods. A similar result has been found by Sabirov et al. [33] by using equal channel angular pressing method. They found the uniform distribution of particle by using quadrat method, and increase in fracture toughness of the composite material. Many researchers studied the mechanical properties of the composites fabricated by stir casting [34,35], ingot metallurgy process [36], and liquid metal infiltration [37], in all the processes however they found uniform distribution of reinforcement.

\subsection{Grain size and, weight percentage of reinforcement}

Grain size and weight percentage of reinforcement is the most important aspect of process development. The Grain size and weight percentage plays 
Table 2. The porosity percent of micro and nano-composite fabricated by compo and stir casting process data from [45].

\begin{tabular}{|c|c|c|}
\hline Micro/nano-composite & $\begin{array}{l}\text { Porosity } \\
\text { (\%) (Stir casting) }\end{array}$ & $\begin{array}{l}\text { Porosity } \\
\text { (\%) (Compo casting) }\end{array}$ \\
\hline A356 & 1.11 & 1.11 \\
\hline A356-1 wt. $\%$ micro- $-\mathrm{Al}_{2} \mathrm{O}_{3}$ & 1.18 & 1.15 \\
\hline A356-3 wt. $\%$ micro- $\mathrm{Al}_{2} \mathrm{O}_{3}$ & 2.05 & 2.05 \\
\hline A356-5 wt. $\%$ micro- $-\mathrm{Al}_{2} \mathrm{O}_{3}$ & 2.9 & 2.85 \\
\hline A356-7.5 wt. \% micro- $\mathrm{Al}_{2} \mathrm{O}_{3}$ & 5.6 & 5 \\
\hline A356-1 wt. $\%$ nano- $-\mathrm{Al}_{2} \mathrm{O}_{3}$ & 1.18 & 1.12 \\
\hline A356-2 wt. $\%$ nano- $-\mathrm{Al}_{2} \mathrm{O}_{3}$ & 1.62 & 1.5 \\
\hline A356-3 wt. $\%$ nano- $-\mathrm{Al}_{2} \mathrm{O}_{3}$ & 2.41 & 2.25 \\
\hline A356-4 wt. $\%$ nano- $-\mathrm{Al}_{2}^{2} \mathrm{O}_{3}^{3}$ & - & 3.5 \\
\hline
\end{tabular}

Table 3. The ductility of the micro and nano-composite fabricated by compo and stir casting process data from [45].

\begin{tabular}{|c|c|c|}
\hline Micro/nano-composite & $\begin{array}{l}\text { Ductility } \\
\text { (\%) (Stir casting) }\end{array}$ & $\begin{array}{l}\text { Ductility } \\
\text { (\%) (Compo casting) }\end{array}$ \\
\hline A356 & 1.55 & 1.55 \\
\hline A356-1 wt. \% micro- $\mathrm{Al}_{2} \mathrm{O}_{3}$ & 1.45 & 1.48 \\
\hline A356-3 wt. \% micro- $\mathrm{Al}_{2} \mathrm{O}_{3}$ & 0.94 & 1 \\
\hline A356-5 wt. \% micro-Al ${ }_{2} \mathrm{O}_{3}$ & 0.83 & 0.87 \\
\hline 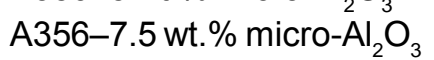 & 0.65 & 0.7 \\
\hline A $356-1$ wt. $\%$ nano- $\mathrm{Al}_{2} \mathrm{O}_{3}$ & 1.31 & 1.37 \\
\hline A356-2 wt. $\%$ nano- $\mathrm{Al}_{2} \mathrm{O}_{3}$ & 1.21 & 1.29 \\
\hline A356-3 wt. $\%$ nano- $-\mathrm{Al}_{2} \mathrm{O}_{3}$ & 1.12 & 1.19 \\
\hline A356-4 wt. $\%$ nano- $-\mathrm{Al}_{2} \mathrm{O}_{3}^{3}$ & - & 0.74 \\
\hline
\end{tabular}

a crucial role in improving physical and mechanical properties of the AMMCs which can be determined by measuring the density, hardness and tensile strength values. Varol and Canakci [38] reported that, density value decreases and hardness value increases with an increase in the weight fraction of reinforcement. Similar results are reported by $W$. Zhou and Z. M. Xu [39]. This is in agreement with Pramanik et al. [40] that deformation behaviour, especially hardness value typically depends on the volume percentage of reinforcement. Muthukrishnan and Paulo Davim [41] obtained a result in contrast to the result obtained by the above researchers. The authors investigated the effect of reinforcing percentage on the tool wear mechanism, in machining the metal matrix composites fabricated by stir casting technique. They found that increase in the percentage of reinforcement has no effect on improving the mechanical properties but increases the tool wear. The reason for this may be due to the poor wetting action between the reinforcement and matrix mate- rial. In a very recent work carried out by Pramanik [42], wear behaviour of $6061 \mathrm{Al}$ alloy matrix reinforced with $10 \%$ volume fraction of $\mathrm{Al}_{2} \mathrm{O}_{3}$ was studied. Author found that significant improvement in the wear resistance of the specimen to the various parameters. Muthukrishnan et al. [43] carried a detailed discussion on fabrication of $\mathrm{Al} / \mathrm{SiC} / \mathrm{B}_{4} \mathrm{C}$ hybrid metal matrix composites fabricated by stir casting technique. They reported that, weight percentage of reinforcement play a significant role in improving the surface roughness of the cast composites. Basavarajappa and Paulo Davim [44] have also investigated the influence of graphite particles on surface roughness and chip formation of hybrid metal matrix composites fabricated by liquid metallurgy technique. They found that this method plays a significant role in increasing the surface roughness value of graphite reinforced Al 2219/15SiCp composite. Table 2 and Table 3 show the grain size and weight percentage variation of micro and nano composites for two different techniques viz stir cast- 


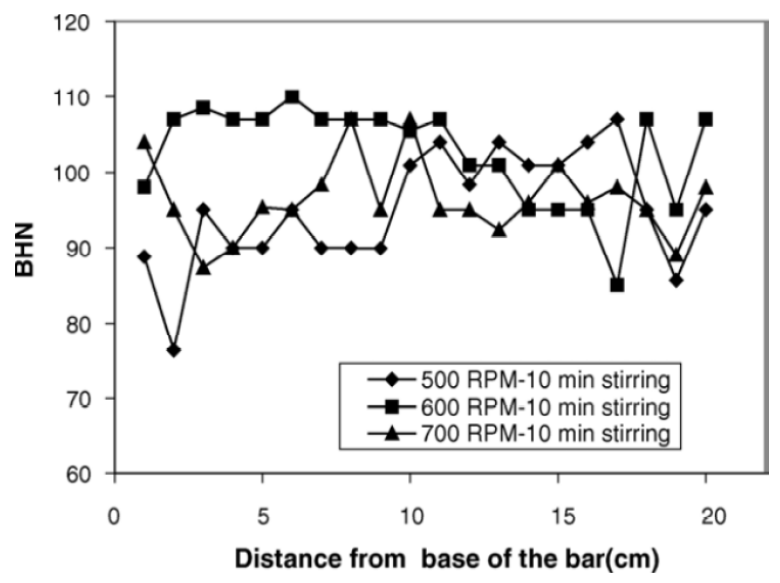

Fig. 1. Effect of stirring speed on hardness of Al$\mathrm{SiC}$ MMC fabricated at 10 min stirring. Reprinted with permission from Balasivanandha Prabu, L. Karunamoorthy, S. Kathiresan, B. Mohan // Journal of Materials Processing Technology 171 (2006) 268, ( 2005 Elsevier.

ing and compocasting. Table 2 clearly shows an increase in porosity with increasing in micro and nano alumina and decrease in liquid metal flow, due to poor nucleation at the $\mathrm{Al}_{2} \mathrm{O}_{3}$ particulate surfaces. Investigators S.A. Sajjadi et al. [45] reported that good wettability of particles in compo-casing and low porosity compared to stir casting process. Lower the porosity, better the wettability between the matrix and the reinforcement particles as well as the lower volume shrinkage of the composite 46 . A more realistic depiction has been given by Hansang Kwon et al. [47] based on advanced powder processing method. By combining hot extrusion and spark plasma technique, they founded that the addition of 5 vol.\% carbon nanotube reinforced AMMC, increases the strength by three times that of pure Al. In general, a particle of different size produces different amounts of strengthening, as the grain size decreases, increases the strength of the composites and decreases porosity.

\subsection{Stirring speed, stirring time, and temperature}

Processing temperature, stirring time and holding time, plays a key role for the uniform distribution of particles in improving the mechanical properties of the composites. Balasivanandha Prabu et al. [48] pointed out that particle clustering is more with lower stirring speed and lower stirring time. Increase in stirring speed to $400 \mathrm{rpm}$ and stirring time for 10 min resulted in better distribution of particles and uniform hardness values. And at higher tempera-

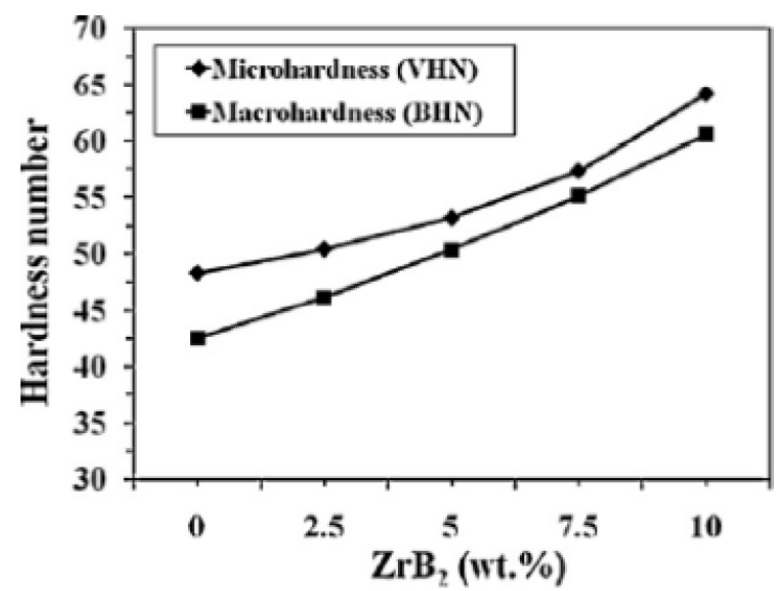

Fig. 2. Effect of weight percentage of $\mathrm{ZrB}_{2}$ on micro hardness and macro hardness of AA6061MMC. Reprinted with permission from I. Dinaharan, N. Murugan, Siva Parameswaran // Materials Science and Engineering A 528: 18 (2011) 5733, ( 2011 Elsevier.

ture, particle settling is noticeable. Furthermore, they concluded that beyond certain stir speed the properties degraded again. A similar variation has been documented by A.A.N. Azim et al. [49] for a composite produced by stir casting method. Sozhamannan et al. [50] found that, higher the holding time greater the formation of particle clustering with increase in temperature. Stirring speed should be continued for a few minutes, but not too high before the material is poured into the mould. Guan Li-na et al. [51] reported that the uniform distribution of reinforcement and increase in tensile properties with decreasing the stirring temperature to $953.15 \mathrm{~K}$ $\left(640^{\circ} \mathrm{C}\right)$ and increasing the stirring time to 30 mints. It is important to note that sole attention is needed for fabrication of AMMCs by stir casting route, in order to disperse the uniform distribution of reinforcement and to improve the mechanical properties.

\section{DISCUSSION}

\subsection{Process modeling}

Defects formed in the composites during the Stir casting process, will depreciate their properties. Different kinds of defects such as black inclusions related to agglomeration of different reinforcements, porosity related to gas and $\mathrm{SiC}$ agglomeration are discussed in this paper. This results in significant characterization of processing parameters such as stirring speed and stirring time, low pressure and temperature, weight percentages of reinforcement and fabrication methods. And micro structural evo- 


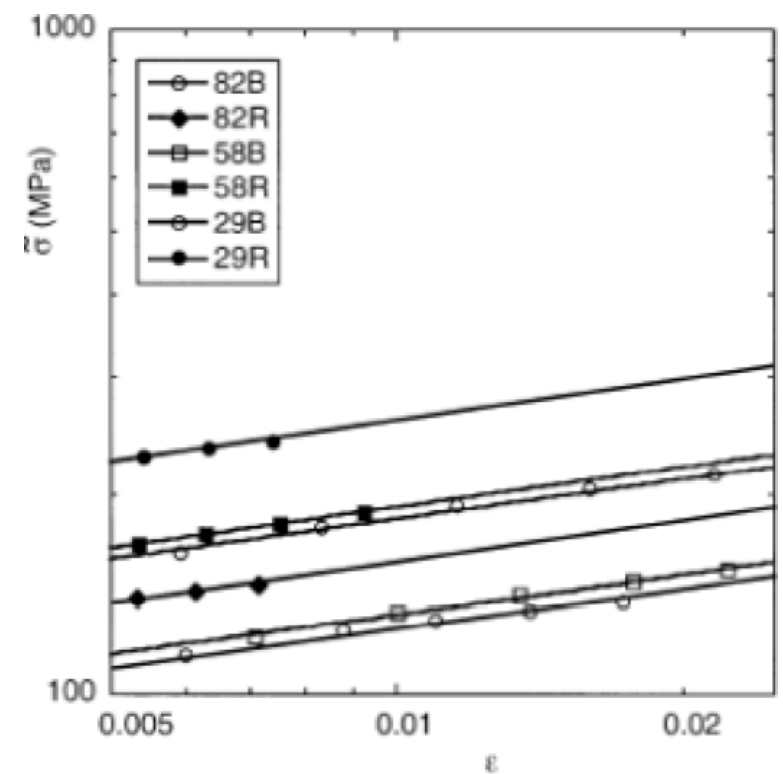

Fig. 3. Effective stress vs. strain (In-In plots) for the various B4C-Al composites. Reprinted with permission from Marianna Kouzel, Christopher San Marchi, Andreas Mortensen // Materials Science and Engineering A 337 (2002) 264, @ 2002 Elsevier.

lution, including grain size, grain boundary character, redistribution of dispersoids. Based on these investigations, a technique for improving the quality of composites fabricated by a stir casting method is proposed. In this section, the present state of understanding of mechanical properties, wear properties, micro structural properties, morphological properties and technological fields of stir casting technique are reviewed here.

Mechanical properties of AMMCs using stir casting method, depends on its stirring speed and stirring time, low pressure and temperature, the weight percentage of reinforcement. And consequently, the mechanical properties can be controlled by a proper adjustment of stirring speed and stirring time and the weight percentage of reinforcement. Experimental work by Balasivanandha Prabu et al. [48] indicated that increasing the speed, increases the entrapment of reinforcement in the composite. With further increase in the speed, leads to reduction in amount of incorporation of reinforcement. This may be due to increasing in interparticle distance, which reduces the hardness of the composites. A similar variation has been presented by Tham et al. [52] for a composite produced by disintegrated melt deposition method. Therefore, the mechanical properties of the stir casting composites can be improved by means of increasing the speed to some extent, Fig. 1.
Balasivanandha Prabu et al. [48] observed poor nucleation at the SiC area and slow down of the liquid metal flow. And they concluded that at higher speeds porosity is more. This is in agreement with Kennedy et al. [53] they suggested that, vigorous stirring, enables oxide skins, gases and contaminants to be entrained in the melt. Hsu et al. [54] suggested that specimens prepared from friction stir casting are fully dense, and pores free. Abbasipour et al. [55] investigated the method of fabrication of aluminum alloys reinforced with carbon nanotube (CNTs) by special reinforcement method of stir casting and Compo casting method. They pointed out that, stirring action of stirrer at 500 RPM uniformly distribute the CNTs and prevent gravity segregation and no CNT agglomerates in the composite coating.

Dinaharan et al. [56] developed AA6061 reinforced with zirconium boride $\left(\mathrm{ZrB}_{2}\right)$ particles by the in situ reaction of $\mathrm{K}_{2} \mathrm{ZrF}_{6}$ and $\mathrm{KBF}_{4}$ salts with molten aluminium. They found that with the increase in weight percentages of $\mathrm{ZrB}_{2}$ both micro hardness and macro hardness of AMMCs increases Fig. 2. Furthermore $\mathrm{ZrB}_{2}$ particles may increase the dislocation density resulting in superior hardness. At the end they concluded that matrix alloy AA6061 possesses good castability, weldability, reasonable strength, corrosion and wear resistance. In contrast to the in situ process, Rajan and Pai et al. [57] using, ex-situ (centrifugal casting) process found that, Al-SiC functionally graded material has shown graded distribution of $\mathrm{SiC}$ towards the outer periphery and $\mathrm{SiC}$ and Graphite towards inner periphery due to hindered settling phenomena. This process has also resulted in improving the mechanical properties of the composites. In order to achieve, better performance of the composites the homogeneous distribution of reinforcement is an important factor [58].

Fig. 3 shows the effective stress vs. strain (In-In plots) for the various $\mathrm{B}_{4} \mathrm{C}-\mathrm{Al}$ composites. Recently Marianna Kouzel et al. [59] found that damage in the materials during tensile straining does not result in a significant increase of their volume. They also concluded that, tensile properties of infiltrating $\mathrm{B}_{4} \mathrm{C}$-/Al composites can be tailored by not only decreasing the size of the particles, but also increasing the reaction between the constituents, this results in a higher composite flow stress but at the expense of lower elongation to failure. A similar result has been proposed by S. Kumar et al. [60] for the composites fabricated by salt reaction route method. The authors reported that, the fine refine- 

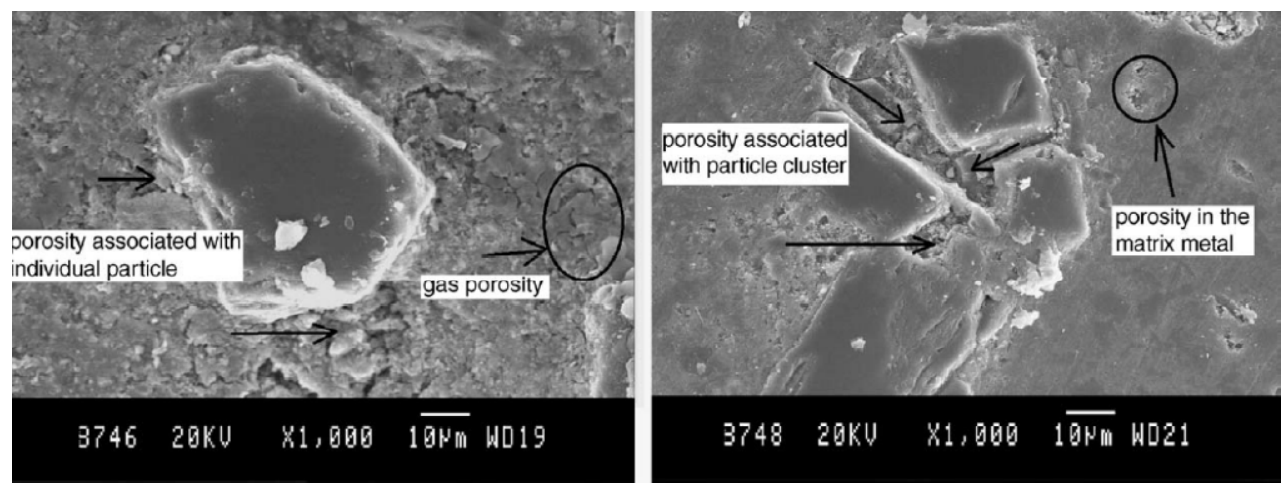

Fig. 4. SEM micro graphs of a typical porosity cluster in MMC. Reprinted with permission from Balasivanandha Prabu, L. Karunamoorthy, S. Kathiresan, B. Mohan // Journal of Materials Processing Technology 171 (2006) 268, ( 2005 Elsevier.

ment of $\alpha$-AI SDAS and eutectic Si particle size in addition to the presence of fine $\mathrm{TiB}_{2}$ particles responsible for improvement in properties of $\mathrm{Al}-7 \mathrm{Si} /$ $\mathrm{TiB}_{2}$ composites by increasing the mechanical properties such as hardness, tensile strength, and Young's modulus of the material. The effect of stir casting parameters for temperature was further examined by Li Gui-Rong et al. [61]. They reported that in the presence of $\mathrm{CaF}_{2}$ and $\mathrm{LiCl}$ which acts as fluxes to accelerate the emulsion process of $\mathrm{K}_{2} \mathrm{TiF}_{6}$ and decrease the in situ reaction temperature from $1073.15 \mathrm{~K}-993.15 \mathrm{~K}\left(800^{\circ} \mathrm{C}\right.$ to $\left.720^{\circ} \mathrm{C}\right)$. The nucleation rate of Al3Ti particles is accelerated and the sizes of particles are refined. This bonding condition is helpful to increase the mechanical properties of composites. Conventional stir casting has a major drawback, especially in liquid state condition such as, mechanical stirring, mixing of particles into melt to a certain extent, returning of particles to the surface when stirring action is stopped.

More recently an attempt was made by Abhishek Kumar et al. [62] to develop aluminum alloy MMC by using the electromagnetic stir casting method. They reported that, in electromagnetic stirring process the material rotates continuously by the electromagnetic field till solidification and homogeneous, uniform settling of reinforcement particles can be obtained through electromagnetic stir casting process. Thus, from the above discussion, it is clear that the stir casting method and various processing parameters not only increases the grain refinement of particles, but also has the tendency to modify the properties of the composites.

\subsection{Morphology}

Nai and Gupta et al. [63] studied the scanning electron microscope (SEM) analysis of AMMCs and observed that, porosity regions are due to porosity associated with individual particle, clustering of reinforcement, micro porosity in the matrix metal, and gas porosity. Olusegun et al. [64] suggested that the porosity in the casting is generally due to: (1) solidification shrinkage (2) dissolved gas in the melt; (3) gas entrapment due to incomplete evacuation; (4) pre porosity due to incomplete infiltration. Abbasipour et al. [55] investigated the method of fabrication of aluminum alloys reinforced with carbon nanotubes (CNTs) by special reinforcement method of stir casting and Compocasting method. They pointed out that, stirring action of stirrer at 500 RPM uniformly distribute the CNTs and prevent gravity segregation and no CNT agglomerates in the composite coating.

Fig. 4 shows the SEM images of A356 aluminum alloys reinforced with carbon nanotubes (CNTs) produced by Stir casting. The specimens were prepared using stir casting method at a stirring speed of 500 RPM. As stated above the work of Balasivanandha Prabu et al. [48] porosity is due to, solidification shrinkage, precipitation of dissolved gasses, gas entrapment, and incomplete infiltration. After examining through the SEM analysis, they found that porosity is also due to, surface roughness, interface wetting, reaction, and so on. They also observed pore nucleation at the reinforcement site, due to particle clustering. They conclude the reason for all these defects is vigorous stirring enables oxide skins, gases and contaminants to be entrained in the melt. This is in agreement with A.R. Kennedy et al. [53] reported that composites can have higher stiffnesses and ductilities due to improved interfacial bonding, caused principally by the increased tendency for nucleation of solid on the particle surfaces. 

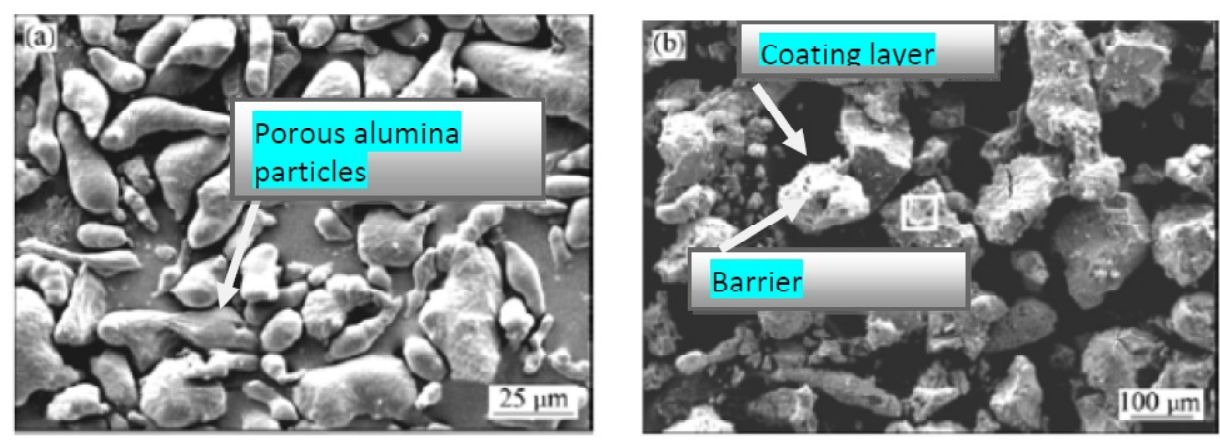

Fig. 5. SEM images of aluminium particles: (a) before coating (b) after coating. Reprinted with permission from B. Abbasipour, B. Niroumand, S. M. Monir Vaghefi // Trans. Nonferrous Met. Soc China 20 (2010) 1561, Copyright $@ 2010$.
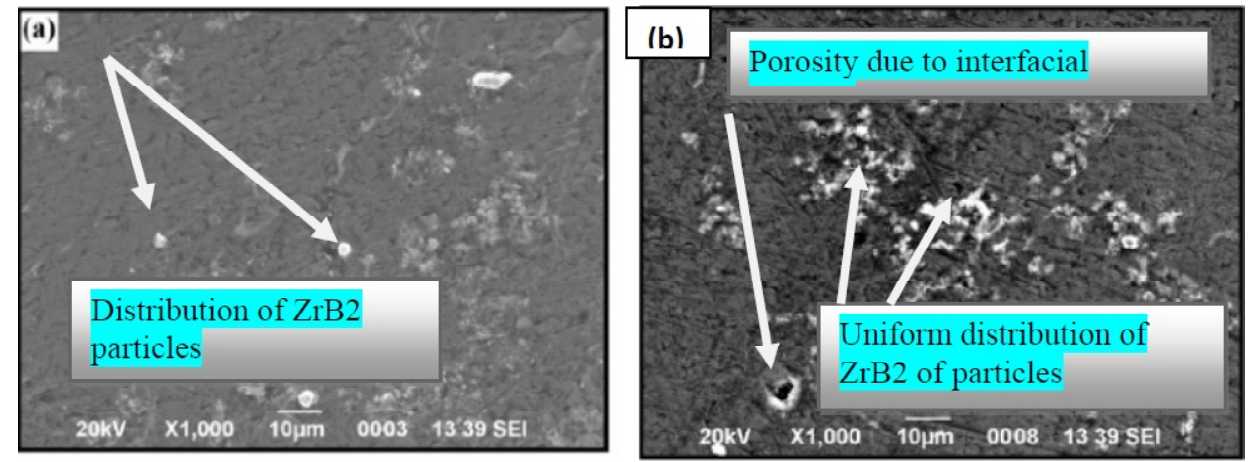

Fig. 6 SEM micrograph of AA6061 MMCs $5 \% \mathrm{ZrB}_{2}$ and 10\% $\mathrm{ZrB}_{2}$. Reprinted with permission from I. Dinaharan, N. Murugan, Siva Parameswaran // Materials Science and Engineering A 528: 18 (2011) 5733, @ 2011 Elsevier.

Fig. 5a Show the SEM images of $\mathrm{Al}_{2} \mathrm{O}_{3}$ before coating. The higher magnification image of the area marked by the rectangle is shown in Fig. 5b. It also shows an increase in the size of the particle due to coating. Figs. 5a and 5b Abbasipour et al. [55] investigated the method of fabrication of aluminum alloys reinforced with carbon nanotubes (CNTs) by special reinforcement method of stir casting and Compocasting method. They pointed out that, stirring action of stirrer at 500 RPM uniformly distribute the CNTs and prevent gravity segregation and no CNT agglomerates in the composite coating. They also suggested that the coating has increased the average size of the aluminum particles and the addition of CNTs to A356 matrix can significantly refine both full liquid and semi-solid cast micro structures. In addition to the stirring speed and weight percentage of reinforcement with respect to the base material, another important process parameter is the solidification time. Hanumanth and Irons [65] found that, when the rate of solidification is high, the suspended $\mathrm{Al}_{2} \mathrm{O}_{3}$ particles in the molten $\mathrm{Al}$ have not been pushed away, and they tend to be stationary. Mortensen and Jin [66] reported that particle pushing could only take place under the condition that the growth velocity of the solid phase is lower than that of the velocity of particle pushing.

Figs. $6 a$ and $6 \mathrm{~b}$ shows the SEM micrographs of AA6061 MMCs containing 5\% $\mathrm{ZrB}_{2}$, and $10 \% \mathrm{ZrB}_{2}$ respectively. The micro graphs show a uniform distribution of $\mathrm{ZrB}_{2}$ particles. The variation in the amount of reinforcement particles is seen with an increased weight percentage of $\mathrm{ZrB}_{2}$. Increasing the weight percentage of $\mathrm{ZrB}_{2}$ they observed the, uniform distribution of $\mathrm{ZrB}_{2}$ particles [56]. Peng Yu et al. [67] developed a new method of uniform distribution of alumina particles in Al-based metal matrix composite. $\mathrm{Al}_{2} \mathrm{O}_{3}$ reinforced $\mathrm{Al}(\mathrm{Zn})$-based $\mathrm{MMC}$ is fabricated by a displacement reaction method, and excessive amount of $\mathrm{Zn}$ is eliminated by high temperature sintering.

Figs. 7 and 8 shows the SEM micro graphs of the furnace-cooled sample and the oil-quenched sample. Fig. 7 shows some segregation of the $\mathrm{Al}_{2} \mathrm{O}_{3}$ particles in some local regions of the $\mathrm{Al}(\mathrm{Zn})$ matrix. This is due to redistribution of the $\mathrm{Al}_{2} \mathrm{O}_{3}$ particles during the solidification of the Al-rich molten phases. On the other hand, Fig. 8 shows $\mathrm{Al}_{2} \mathrm{O}_{3}$ is closely bonded with the $\mathrm{Al}(\mathrm{Zn})$ matrices resulted in no structural defects, such as voids or cracks, in the 


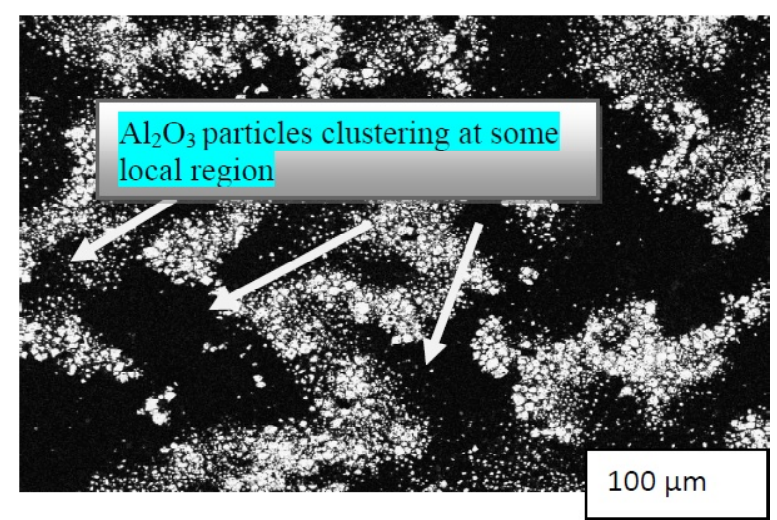

Fig. 7 SEM micrograph of the furnace-cooled sample after sintering at $1000^{\circ} \mathrm{C}$. The $\mathrm{Al}_{2} \mathrm{O}_{3}$ particles (bright) are segregated in some local regions in the Al (Zn) matrix (dark). Reprinted with permission from Peng Yu, Cheng-Ji Deng, Nan-Gang Ma, H.L. Dickon $\mathrm{Ng} / /$ Materials Letters 58 (2004) 679, Copyright ( 2003.

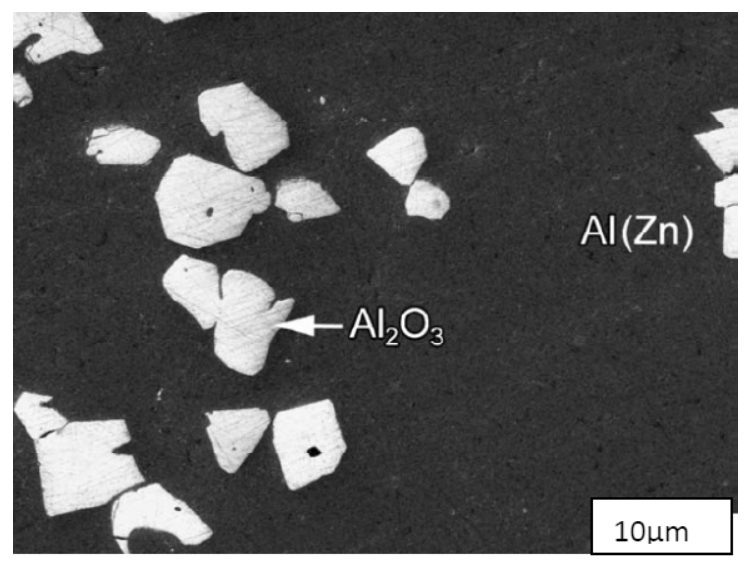

Fig. 8. SEM micrograph of the oil-quenched which shows that the average size of the $\mathrm{Al}_{2} \mathrm{O}_{3}$ Particles are about $10 \mu \mathrm{m}$. Structural defects such as cracks or voids have not been found in the $\mathrm{Al} / \mathrm{Al}_{2} \mathrm{O}_{3}$ interface. Reprinted with permission from Peng Yu, Cheng-Ji Deng, Nan-Gang Ma, H.L. Dickon Ng // Materials Letters 58 (2004) 679 Copyright @ 2003.

$\mathrm{Al}(\mathrm{Zn}) / \mathrm{Al}_{2} \mathrm{O}_{3}$ interface. And also $\mathrm{Al}_{2} \mathrm{O}_{3}$ particles are distributed more uniformly in the $\mathrm{Al}(\mathrm{Zn})$ matrices of the oil-quenched sample than those in the $\mathrm{Al}(\mathrm{Zn})$ of the furnace-cooled sample. This is in agreement with Seyed Abdolkarim Sajjadi et al. [68] at low pressure $(400 \mathrm{MPa})$ and temperature $853.15 \mathrm{~K}\left(580^{\circ} \mathrm{C}\right)$ reduction in porosity level is less, and bonding between the matrix and inter metallic particles are not strong. They claimed that increasing sintering temperature and pressure increases the contacts between the reinforcements and matrix material and enhance the reaction at the interface, which results in significant improvement in bonding.

\section{CONCLUSION}

This review article gives a concise introduction to the various processing techniques and their influencing parameters such as fabrication method, grain size and weight percentage of reinforcement, stirring speed, stirring time and temperature is discussed first. Advanced technologies that have been made recently are also discussed. It is found from the various research works that processing parameters are crucial to produce sound and defect free casting.

The large bunch of improved mechanical properties achieved at every processing parameter together with the ease of production through simple processes such as stir casting, sol-gel process, fluxcasting technique, plasma spray forming, compocasting combination of hot extrusion and spark plasma sintering, directly applicable by various methods makes $\mathrm{SiC}, \mathrm{Al}_{2} \mathrm{O}_{3}$, facing sand etc. reinforced composites a very promising new class of materials. The influence of various process parameters at different operating conditions, size, shape, and morphology of reinforcement particles is discussed in detail. Certainly, the outstanding combination of their key properties and potentially lower production costs gravel the way to the much broader range of applications. Furthermore, the increase in stirring speed, the weight percentage of reinforcement, to a suitable range, and cost effective fabrication method required to display significant properties enhancement makes them competitive with other materials. One of the most critical processing steps that must be optimized, as reported by many authors, is the solidification time, result in porosity. Nevertheless, a lot of research remains to be carried out in order to fully understand factors such as solidification time, dissolved gas in the melt, gas entrapments due to incomplete evacuation, pre-porosity due to incomplete infiltration, yielding the different AMMC structures. Furthermore, a much more understanding of the actual structure/property relationships has to be satisfied in some important area such as micro structure, physical and mechanical properties. Finally, it is important to pointing out that new methods of fabrication of AMMC have recently been reported and their ability to form uniform distribution of reinforcement with enhanced properties has been proposed. For example, $\mathrm{Al}_{2} \mathrm{O}_{3}$ and $\mathrm{A} 359$ filled Electromagnetic stir casting method has shown to be capable of removing any moisture in the particles and the matrix materials burns off so it reduces the level of porosity thereby increases the perform- 
ance of the composites. Recent processing techniques in the development of aluminium metal matrix composites involve high cost and maintenance. However, no special attention, and care is needed in conventional method of fabrication. Because of easy of fabrication, stir casting is the most economical processing route. Cost reductions can be achieved by using cheaper reinforcements. Particulate reinforcements are relatively cheaper and easily available such as, facing sand, $\mathrm{SiC}, \mathrm{Al}_{2} \mathrm{O}_{3}$, fly ash etc.

\section{REFERENCES}

[1] Y.Q. Liua, H.T. Cong, W. Wang, C.H. Sun and H.M. Cheng // Materials Science and Engineering A 505 (2009) 151.

[2] F. Berto and P. Lazzarin // Materials Science and Engineering $R 75$ (2014)1.

[3] Hülya Kaftelen, Necip Ünlü, Gültekin Göller, M. Lütfi, Öveçoglu and Hani Henein // Composites: Part A 42 (2011) 812.

[4] H.X. Peng, Z. Fan and J.R.G. Evans // Materials Science and Engineering A 303 (2001) 37.

[5] X.C. Tong and A. K. Ghosh // Journal of materials science 36 (2001) 4059.

[6] Yong Li and Terence G. Langdon // Acta Mater 45 (1997) 4797.

[7] R.A. Saravanan and M.K. Surappa // Materials Science and Engineering A 276 (2000) 108.

[8] C. M. Friend // J Mater. Sci 22 (1987) 3005.

[9] Mattika Bunma, Pornoan Subarporn, Rattanaporn Bobuangern, Thanapon Patthannkitdamrong, Thasanai Thuanwong and Tapany Patcharawit // Journal of Metals, Materials and Minerals 21 (2011) 85.

[10] Mitsuaki Matsumuro and Tadashi Kitsudo // Materials Transactions 47 (2006) 2972.

[11] A.M. Redstern, E.M. Klier, A.M. Brown and D.C. Dunand // Materials Science and Engineering A 201 (1995) 88.

[12] A.M.S. Hamouda, S. Sulaiman, T.R. Vijayaram, M. Sayuti and M.H.M. Ahmad // Journal of Achievements in Materials and Manufacturing Engineering 25 (2007) 12.

[13] S. Amirkhanlou and B. Niroumand // Trans. Nonferrous Met. Soc. China 20 (2010) 788.

[14] A.E. Karantzalis, S. Wyatt and A.R. Kennedy // Materials Science and Engineering A 237 (1997) 200.

[15] Yuyong Chem and D.D. Lchung // Journal of material science 29 (1994) 6069.
[16] L.A. Dobrzański, M. Kremzer, A.J. Nowak and A. Nagel // Journal of Achievements in Materials and Manufacturing Engineering 20 (2007) 1.

[17] L.A. Dobrzański, M. Kremzer, A.J Nowak and A. Nagel // Journal of Archives of Materials Science and Engineering 36 (1) (2009) 5.

[18] M. Muratoglu, O. Yilmaz and M. Akso // Journal of Materials Processing Technology 178 (2006) 211.

[19] A. Włodarczyk-Fligier, L.A. Dobrzański, M. Kremzer and M. Adamiak // Journal of Achievements in Materials and Manufacturing Engineering 27 (2008) 99.

[20] L.A. Dobrzański, M. Kremzer and M. Adamiak // Journal of Achievements in Materials and Manufacturing Engineering 42 (2010) 1.

[21] N. Chawla, J. J. Williams and R. Saha // Journal of Light Metals 2 (2002) 215.

[22] Roohollah Jamaati and Mohammad Reza Toroghinejad // Materials and Design 31 (2010) 4816.

[23] Zhao Yu-Tao, Zhang Song and Chen Gang // Met. Soc. China 20 (2010) 2129.

[24] N. Barekar, S. Tzamtzis, B. K. Dhindaw, J. Patel, N. Hari Babu and Z. Fan // Journal of Materials Engineering and Performance 18 (2009) 1230.

[25] Muhammad Hayat Jokhio, Muhammad Ibrahim Panhwar and Mukhtiar Aliunar // Journal of Engineering \& Technology 2016 (2016) 1604.

[26] T. Laha, Y. Chen, D. Lahiri and A. Agarwal // Composites: Part A 40 (2009) 589.

[27] S. Naher, D. Brabazon and L. Looney // Journal of Materials Processing Technology 143 (2003) 567.

[28] A. Tony Thomas, R. Parameshwaran, A. Muthukrishnan and M. Arvind Kumaran // Procedia Material science 5 (2014) 1182.

[29] Chen Guo-qin, Xiu Zi-Yang, Yang Wen-Shu, Jiang Long-Tao and Wu Gao-Hui // Trans. Nonferrous Met. Soc. China 20 (2010) 2143.

[30] Chi-Hoon Jeon, Yong-Ha Jeong, Jeong-Jin Seo, Huynh Ngoc Tien, Sung-Tae Hong, Young-Jin Yum, Seung-Hyun Hur and KwangJin Lee // International Journal of Precision Engineering and Manufacturing 15 (2014) 1235.

[31] M. Saravanan, R.M. Pillai, K.R. Ravi, B.C. Pai and M. Brahmakumar // Composites Science and Technology 67 (2007) 1275. 
[32] Jingyu Yang and D.D.L. Chung // Journal of material science 24 (1989) 3605

[33] I. Sabirov, O. Kolednik, R.Z. Valiev and R. Pippan // Acta Materialia 53 (2005) 4919.

[34] P. Appendino. C. Badini, F. Marino and A. Tomasi // Materials Science and Engineering A 135 (1991) 275.

[35] K. Gopinath, A.K. Gogia, S.V. Kamat, R. Balamuralikrishnan and U. Ramamurty // Acta Materialia 57 (2009) 3450.

[36] D.J. Lloyd // Composite Science and Technology 35 (1989) 159.

[37] D.K. Balch, J.G. O'Dwyer, G.R. Davis, C.M. Cady, G.T. Gray III and D.C. Dunand // Materials Science and Engineering: A 391(12) (2005) 408.

[38] T. Varol and A. Canakci // Metals and Materials International 19 (2013) 1227.

[39] W. Zhou and Z.M. Xu // Journal of Materials Processing Technology 63 (1997) 358.

[40] A. Pramanik, L.C. Zhang and J.A. Arsecularatne // J Composites Science and Technology 68 (2008) 1304.

[41] N. Muthukrishnan and J. Paulo Davim // J Journal of Mechanical Engineering Research 3 (2011) 15.

[42] A. Pramanik // J Trans. Nonferrous Met. Soc. China 26 (2016) 348.

[43] N. Muthukrishnan, T. S Mahesh Babu and R. Ramanujam // J Journal of the Chinese Institute of Industrial Engineers 29 (2012) 515.

[44] S. Basavarajappaa and J. Paulo Davim // J Materials Research 16(2013) 990.

[45] S.A. Sajjadi, H.R. Ezatpour and Torabi Parizi // Materials and Design 34 (2012) 106. [46]

A. Urena, E.E. Martinez, P. Rodrigo and L. Gil // Composites Science and Technology 64 (2004) 1843.

[47] Hansang Kwon, Mehdi Estili, Kenta Takagi, Takamichi Miyazaki and Akira Kawasaki // CARBON 47 (2009) 570.

[48] S. Balasivanandha Prabu, L. Karunamoorthy, S. Kathiresan and B. Mohan // Journal of Materials Processing Technology 171 (2006) 268.

[49] A.A.N. Azim, Y. Shash, S.F. Mostafa and A. Younan // Journal of Materials Processing Technology 55 (1995) 199.

[50] G.G. Sozhamannan, S. Balasivanandha Prabu and V.S.K. Venkatagalapathy //
Journal of Surface Engineered Materials and Advanced Technology 2 (2012) 11.

[51] Guan Li-Na, Geng Lin, Zhang Hong-Wei and Huang Lu-Jun // Trans. Nonferrous Met. Soc. China 2 (2011) 1274.

[52] L.M. Tham, M. Gupta and H. Cheng // Journal of Materials Processing Technology 89 (1999) 128.

[53] A.R. Kennedy, A.E. Karantzalis and S.M. Wyatt // J. Mater. Sci. 34 (1999) 933.

[54] C.J. Hsu, P.W. Kao and N.J. Ho // Scripta Materialia 53 (2005) 341.

[55] B. Abbasipour, B. Niroumand and S. M. Monir Vaghefi // Trans. Nonferrous Met. Soc China 20 (2010) 1561.

[56] I. Dinaharan, N. Murugan and Siva Parameswaran // Materials Science and Engineering A 528 (2011) 5733.

[57] T.P.D. Rajan and B.C. Pai // Trans Tech Publications Switzerland 690 (2011) 157.

[58] B. Fogagnolo, M.H. Robert, E.M. Ruiz-Navas and J.M. Torralba // Journal of Materials Science 39 (1) (2004) 127.

[59] Marianna Kouzel, Christopher San Marchi and Andreas Mortensen // Materials Science and Engineering A 337 (2002) 264.

[60] S. Kumar, M. Chakraborty, V. Subramanya Sarma and B. S. Murty // Wear 265 (2008) 134.

[61] LI Gui-Rong, Wang Hong-Ming, Zhao Yu-Tao, Chen Deng-Bin, Chen Gang and Cheng XiaoNong // Trans. Nonferrous Met. Soc. China 20 (2010) 577.

[62] Abhishek Kumar, Shyam Lal and Sudhir Kumar // Journal of mater research and technology 3 (2013) 250.

[63] S.M.L. Nai and M. Gupta // Compos. Struct. 57 (2002) 227.

[64] J. Olusegun, llegbusi and Jijin Yang // Metall. Mater. Trans. A 31 (2000) 2069.

[65] G.S. Hanumanth // Metallurgical and materials transactions B 27B (1996) 663.

[66] A. Mortensen and I. Jin // Int.Met. Rev 37 (1992) 101.

[67] Peng Yu, Cheng-Ji Deng, Nan-Gang Ma and H.L. Dickon Ng // Materials Letters 58 (2004) 679.

[68] Seyed Abdolkarim Sajjadi, Maryam Abbasi and Mazyar Azadbeh // Materials Sciences and Applications 2 (2011) 1340. 